Clinical or electrical seizures were not present during the first $72 \mathrm{~h}$ nor the staging of HIE increased during this period in any of the patients. Mean CSF NSE at $72 \mathrm{~h}$ was $26 \mathrm{ng} / \mathrm{mL}(+/-7.8)$. Conclusions Clinical status of infants with mild HIE at $6 \mathrm{~h}$ of age does not worsen in the following $72 \mathrm{~h}$. The aEEG traces are consistently normal and subclinical seizures are uncommon.

\section{PO-0449 CORRELATION BETWEEN AMPLITUDE INTEGRATED EEG (AEEG) AND CLINICAL EVALUATION IN NEWBORN INFANTS WITH HYPOXIC-ISCHAEMIC ENCEPHALOPATHY (HIE)}

M Camprubí, A Alarcón Allen, G Arca-Diaz, MS León, T Agut, A Garcia-Alix. Neonatology, Agrupació Sanitaria Clínic-Sant Joan de Déu, Barcelona, Spain

\subsection{6/archdischild-2014-307384.1090}

Background and aims Both clinical staging and aEEG during the first $6 \mathrm{~h}$ correlate with outcome in neonates with HIE and are used for inclusion of patients in therapeutic hypothermia (TH) trials and clinical protocols. However, little is known about the correlation between clinical evaluation and aEEG tracing these infants.

Objective To determine the correlation between clinical evaluation and aEEG during the first $6 \mathrm{~h}$ of life in HIE infants.

Methods Prospective observational study of HIE infants admitted in a tertiary unit during 2009 to 2011 . A single clinician performed clinical exam before cooling indication. Staging of encephalopathy was done according to a validated scoring system. aEEG recording was performed from admission. Pattern classification was ranked from 1 to 5 (with higher scores indicating more suppressed traces).

Results 55 patients were included; $21.9 \%$ had mild, $27.3 \%$ moderate and $50.9 \%$ severe encephalopathy. The mean duration of a EEG recording was $71.52 \pm 34.6 \mathrm{~h}$ and aEEG started at a mean age of $4.3 \pm 3.1 \mathrm{~h}$. We found a correlation between aEEG and the following items: ability to awaken (AA) $(r=0.72)$, spontaneous movements $(r=0.73)$ and posture $(r=0.74)$. No correlation was observed between aEEG and myotatic reflexes $(\mathrm{r}$ $=0.44)$ and breathing pattern $(r=0.37)$. AA correlated with HIE stage $(r=0.85)$. Further, HIE stage correlated with the score of aEEG tracing at admission $(\mathrm{r}=0.77)$.

Conclusion aEEG tracing correlates well with the degree of altered alertness and with the clinical grading of HIE, supporting the validity of this tool to reflect the severity of brain dysfunction before cooling in infants with HIE.

\section{PO-0450 CORRELATION BETWEEN EARLY CEREBRAL FUNCTION MONITORING (CFM) AND CSF NEURON-SPECIFIC ENOLASE (NSE) IN NEONATES WITH HYPOXIC ISCHAEMIC ENCEPHALOPATHY (HIE)}

M Camprubí, A Alarcón Allen, MS Leon, G Arca-Díaz, T Agut, A Valls, A Garcia-Alix. Neonatology, Agrupació Sanitaria Clínic-Sant Joan de Déu, Barcelona, Spain

\subsection{6/archdischild-2014-307384.1091}

Background and aims aEEG predicts outcome in newborns with HIE. CSF-NSE serves as surrogate for HI brain injury. Little is known about the correlation between early aEEG and CSF-NSE within the first $72 \mathrm{~h}$ of age.

\begin{tabular}{|c|c|c|c|c|}
\hline & Total HIE N=55 & $\begin{array}{l}\text { Mild HIE } \\
(\mathrm{N}=12) 21.8 \%\end{array}$ & $\begin{array}{l}\text { Moderate HIE } \\
(\mathrm{N}=15) 27.3 \%\end{array}$ & $\begin{array}{l}\text { Severe HIE } \\
(\mathrm{N}=28) 50.9 \%\end{array}$ \\
\hline Outborn\% & $66.1 \%$ & $16.7 \%$ & $73.3 \%$ & $85.7 \%$ \\
\hline Weight $(\mathrm{g})$, mean (SD) & $3035(580)$ & $3056(505)$ & $3075(554)$ & $2994(584)$ \\
\hline Death & $33.9 \%$ & $0 \%$ & $6.7 \%$ & $64.3 \%$ \\
\hline
\end{tabular}

Aim To examine the correlation between early aEEG and CSF NSE concentrations in neonates with HIE.

Methods Prospective observational study of term infants with HIE admitted at Agrupació Sanitaria Sant Joan de Déu-Clinic from 2009 through 2011. HIE was clinically graded according to a validated system. Patients with significant HIE underwent therapeutic hypothermia. CFM was performed in all cases. Pattern classification was ranked from 1 to 5 (with higher scores indicating more suppressed traces). The worst CFM tracing within the first $6 \mathrm{~h}$ and 6 to $12 \mathrm{~h}$ was correlated with CSF NSE performed at $12 \mathrm{~h}$ and $72 \mathrm{~h}$.

Results Clinical characteristics of patients are summarised in the Table 1.

The degree of neonatal encephalopathy was related with CSF-NSE concentrations at $12\left(\mathrm{r}_{\mathrm{s}}=0.38\right)$ but overall at $72 \mathrm{~h}$ of life $\left(r_{\mathrm{s}}=0.83\right)$. aEEG traces at $6 \mathrm{~h}$ but also at $6-12 \mathrm{~h}$ were correlated with CSF-NSE concentration at $12 \mathrm{~h}\left(\mathrm{r}_{\mathrm{s}}=0.544\right.$ and $\left.r_{s}=0.529\right)$ and even more significant at $72 \mathrm{~h}\left(r_{\mathrm{s}}=0.790\right.$ and $r_{\mathrm{s}}$ $=0.768$, respectively).

Conclusions Our study provides additional support about aEEG monitoring during the first $12 \mathrm{~h}$ is a reliable biomarker for early estimates of ongoing brain damage in neonatal HIE.

\section{PO-0451 DEFECTS OF CENTRAL NERVOUS SYSTEM: A REVIEW}

${ }^{1} \mathrm{C}$ Castillo Rukoz, ${ }^{1} \mathrm{M}$ Salamanca Campos, ${ }^{2} \mathrm{~S}$ López Agullo, ${ }^{3} \mathrm{~L}$ Sabonet Morente, ${ }^{1}$ A Sanchis Calvo. ${ }^{1}$ Paediatric, Hospital Universitario Dr Peset, Valencia, Spain; ${ }^{2}$ Pathology Anatomy, Hospital Universitario Dr Peset, Valencia, Spain; ${ }^{3}$ Ginecology, Hospital Universitario Dr Peset, Valencia, Spain

\subsection{6/archdischild-2014-307384.1092}

Background and aims Central nervous system (CNS) appears in the $3 \mathrm{rd}$ week of development, derived from the ectodermal sheet and from the neural plate. The frequency of CNS abnormalities ranges from 0.8 to $1.3 / 100$ live births, and neural tube defects (NTD) are the most common. They are associated with a variety of genetic syndromes, chromosomal abnormalities and a variety of environmental factors.

Methods Retrospective descriptive study by review of medical records of patients diagnosed with CNS malformations in pregnancies controlled on our hospital between 2004-2012.

Results There were 17,759 births, 515 fetuses with birth defects diagnosed prenatally and 114 were CNS defects. In 109 cases an abortion was performed, and 5 live births (acraneo, Dandy Walker, ventriculomegaly, choroid plexus cyst, and a combination). Among the aborted fetuses 49 cases were diagnosed of (NTD), 21 brain defects, 9 midline brain abnormalities, 2 cerebellum defects, and 28 syndromic or multiple malformations. Women with affected fetuses present a mean age of 31.5 years (range 14-44 years), 45 were primiparous. The mean gestational age at the time of abortion was 17 weeks (range 11-29).

Conclusions Of all fetuses aborted with prenatal diagnosis of a congenital defect, CNS abnormalities corresponded to $22.5 \%$. 
Women with prenatal diagnosis were not elderly, and most had previous pregnancies without abnormalities.

An important number of CNS malformations are associated with genes or chromosomal syndromes (24\%), and the most frequently isolated cases correspond to NTD (42.2\%), it believes that this group can be prevented by the intake of preconception folic acid.

\section{PO-0452 HYPOXIC-ISCHAEMIC ENCEPHALOPATHY AND PERINATAL INFECTION: A PILOT STUDY}

${ }^{1}$ A Cilla, ${ }^{2}$ J Arnaez, ${ }^{2} \mathrm{~J}$ Suarez, ${ }^{3} \mathrm{G}$ Megias, ${ }^{4} \mathrm{M}$ Cabrerizo, ${ }^{5} \mathrm{~A}$ García-Álix. ${ }^{1}$ Pediatrics, Hospital Universitario de Burgos, Burgos, Spain; ${ }^{2}$ Neonatology Pediatrics, Hospital Universitario de Burgos, Burgos, Spain; ${ }^{3}$ Microbiology, Hospital Universitario de Burgos, Burgos, Spain; ${ }^{4}$ Microbiology, Centro Nacional de Microbiología Instituto de Salud Carlos III, Madrid, Spain; ${ }^{5}$ Neonatology, Hospital Sant Joan de Deu, Barcelona, Spain

\subsection{6/archdischild-2014-307384.1093}

Background Recent studies suggest a synergic effect of infection and hypoxia-ischemia in the causation of perinatal brain damage. Although an infection screening is warranted in cases of hypoxic-ischaemic encephalopathy (HIE), whether this screening should include more infrequent pathogens like neurotropic viruses is controversial.

Objectives To evaluate the importance of perinatal infection in HIE, focusing on neurotropic viruses.

Methods Prospective study including infants above 35 weeks gestation diagnosed of moderate or severe HIE in Burgos University Hospital during the period October 2011-2013. Antenatal and perinatal data were recorded, as well as details of the clinical course in the neonatal period. Serological studies were performed to the mother during pregnancy. Bacterial blood and cerebrospinal cultures, as well as viral tests (Cytomegalovirus, Epstein-Barr virus, Human Herpes virus, Enterovirus, Parechovirus) in cerebrospinal fluid were performed to the newborns at birth.

Results 12 newborns were included in the study. There were no confirmed cases of viral infection. There was a case of bacterial early onset sepsis and three cases of suspected sepsis due to clini$\mathrm{cal}$ and/or analytical signs, but with negative cultures. An elevation of the $\mathrm{C}$ reactive protein (CRP) levels was the sole cause of suspicion in two of these cases.

Conclusions Our results confirm that an infection screening is important in HIE. These pilot results would not support universal screening for viral infection in cases of HIE.

\section{PO-0453 MATURATIONAL CHANGES IN CORTICAL FOLDING IN EXTREMELY PRETERM INFANTS}

${ }^{1} \mathrm{NHP}$ Claessens, ${ }^{1} \mathrm{KJ}$ Kersbergen, ${ }^{2} \mathrm{~F}$ Leroy, ${ }^{3} \mathrm{P}$ Moeskops, ${ }^{3} \mathrm{I}$ Isgum, ${ }^{3} \mathrm{MA}$ Viergever, ${ }^{1} \mathrm{~F}$ Groenendaal, ${ }^{1} \mathrm{LS}$ De Vries, ${ }^{2} \mathrm{~J}$ Dubois, ${ }^{4} \mathrm{M}$ MNL Benders. ${ }^{1}$ Department of Perinatology, Wilhemina Children's Hospital University Medical Center Utrecht, Utrecht, Netherlands; ${ }^{2}$ INSERM Cognitive Neuroimaging Unit U992, CEA DSV I2BM Neurospin Center, Gif Sur Yvette, France; ${ }^{3}$ Image Sciences Institute, University Medical Center Utrecht, Utrecht, Netherlands; ${ }^{4}$ Centre for Developing Brain King's College London UK and Department of Perinatology, Wilhemina Children's Hospital University Medical Center Utrecht, Utrecht, Netherlands

10.1136/archdischild-2014-307384.1094

Background and aim Our aim was to analyse the development of cortical morphology in preterm infants, as alterations in cortical folding affect functional development.
Methods MRI was performed at 30 and 40 weeks corrected age in 19 preterm born infants (gestational age (GA) 24.71-27.86 wks, 11 males). After automatic brain tissue segmentation, ${ }^{1}$ a $3 \mathrm{D}$ reconstruction of the inner cortical surface was computed and cortical sulci were labelled with Brainvisa software. ${ }^{2}$ We measured global sulcal index ( $\mathrm{SI}=$ folded/unfolded surface areas), and per sulcus surface area $\left(\mathrm{SA}, \mathrm{mm}^{2}\right)$ and mean geodesic depth (MGD, mm), all corrected for scan-age.

Results In 10 weeks, SI increased from 0.18 to 1.08 (6 times, 40 wks: right $>$ left). Central sulcus, lateral fissure, and insula increased more in SA (resp. 2.3, 2.6, 1.7-times) than in MGD (resp.1.2, 1.1, 1.3-times). The superior temporal sulcus (STS) expanded in SA with factor 16.3 left and 12.6 right (30 wks: right > left), and factor 1.6 in MGD (30 and 40 wks: right > left). White matter injury in these infants (9 IVH,1 PVHI, 4 treated for PHVD) or GA did not significantly influence cortical morphology changes.

Conclusion Over this short period, cortical folding is immense in preterm newborns, and shows inter-hemispherical asymmetries. Sulci increased more in surface area than in depth, STS showed the largest increase. The influence of brain injury on cortical morphology needs to be elucidated in a larger cohort.

\section{REFERENCES}

1 Chita S, et al. Medical Imaging (2013)

2 Perrot M, et al. Medical Image Analysis (2011)

\section{P0-0454 IMPACT OF SYSTEMATIC PAIN AND SEDATION MANAGEMENT ON OUTCOME OF VERY LOW BIRTH WEIGHT INFANTS}

${ }^{1} \mathrm{P}$ Deindl, ${ }^{2} \mathrm{R}$ Fuiko, ${ }^{3} \mathrm{~T}$ Waldhoer, ${ }^{4} \mathrm{G}$ Kappler, ${ }^{2} \mathrm{~L}$ Unterasinger, ${ }^{2} \mathrm{~V}$ Giordano, ${ }^{2} \mathrm{~T}$ Werther, ${ }^{2} \mathrm{C}$ Czaba, ${ }^{2}$ Geroldinger, ${ }^{2} \mathrm{~A}$ Berger, ${ }^{2} \mathrm{M}$ Olischar. ${ }^{1}$ Department of Neonatology and Pediatric Intensive Care Medicine, University Medical Center Hamburg-Eppendorf, Hamburg, Germany; ${ }^{2}$ Department of Pediatrics and Adolescent Medicine Division of Neonatology Pediatric Intensive Care and Neuropediatrics, Medical University of Vienna, Vienna, Austria; ${ }^{3}$ Department of Epidemiology Center for Public Health, Medical University of Vienna, Vienna, Austria; ${ }^{4}$ Faculty of Psychology Institute for Applied Psychology: Health Development Enhancement Intervention, University of Vienna, Vienna, Austria

\subsection{6/archdischild-2014-307384.1095}

Background and objectives We retrospectively compared shortterm and neurodevelopmental outcome of very low birth weight infants (VLBWI) before $(\mathrm{n}=84)$ and after implementation $(\mathrm{n}=$ 69 ) of a protocol for the management of neonatal pain and sedation.

Methods Opiate exposure, time on mechanical ventilation, inotropic support, details on nutritional aspects, and growth were compared between baseline and after protocol implementation. Infants were evaluated at 12 months corrected age using standardised neurologic examination and Bayley Scales of Infant Development-II.

Results Cumulative mean \pm SD opiate dose (baseline dose of 14 $\pm 39 \mathrm{mg} / \mathrm{kg}$ vs. intervention group dose of $84 \pm 222 \mathrm{mg} / \mathrm{kg}$ morphine equivalents; $\mathrm{p}<0$. 0001) increased after implementation. Time on mechanical ventilation, inotropic support, time on parenteral nutrition, growth, and length of stay were similar before and after implementation. There were no differences in neurodevelopmental outcome variables before and after intervention (MDI: $85 \pm 14$ vs. $84 \pm 16, p=0.6$; PDI: $87 \pm 19$ vs. $83 \pm 19, \mathrm{p}=0.2$; BRS: $74 \pm 27$ vs. $68 \pm 32, \mathrm{p}=0.2$ ). Multiple linear regression analysis identified opiate exposure as a possible risk factor for lower MDI (estimate $=-0.15 ; \mathrm{p}=0.004$ ) 